hanging shelf of rock. Neolithic man generally piled his refuse not at the cave mouth but on one side of the platform.

A number of the caves have been investigated, and from the evidence of the deposits of which details are given, it is apparent that the neolithic colony inhabiting a rock shelter comprised several families, of which the men were hunters, trappers and fishers, while the women collected fruit, nuts and shell-fish. Some degree of agriculture may have been practised. Calcined bones furnish evidence of the use of fire and the practice of roasting game.

\title{
PRODUCTION OF DRUGS WITHIN THE BRITISH EMPIRE
}

$\mathrm{T}$ HE Appendix to the recently published War Memorandum by the Medical Research Council on "Economy in the Use of Drugs in War-Time" (H.M. Stationery Office. $3 d$. net) is of more durable interest than the body of the Memorandum, since it proposes a long-term plan for the cultivation of medicinal plants, whereas the special need for economy in the prescription of scarce drugs will pass with the emergency. The Appendix consists of two lists of drugs the cultivation of which in the British Empire should be encouraged. The first list relates to domestic production and the second to production in the Colonial Empire. It is not proposed to comment, in this note, on all the items named in the Appendix, but to make a few observations based upon the results of experimental work designed to ascertain whether it is feasible to cultivate economically and on a commercial scale, either at home or in some Empire country overseas, certain medicinal plants for the supply of which Great Britain has paid tribute in the past to foreign nations.

Taking first the list of drugs which the Memorandum recommends for production in the United Kingdom, it is proposed to refer to cascara sagrada, ergot, dill, gentian and lobelia. In the past the bulk of Great Britain's large imports of cascara sagrada has been supplied from forests on the American side of the north-west Pacific coast; contributions from the Canadian side have been comparatively small. Experiments have proved that the shrub from which the bark is peeled can be grown in certain soils in Great Britain as a coppice crop on a five-year rotation. An additional advantage of home cultivation is that the wood remaining after the bark has been peeled from it could be converted into charcoal equal in quality to that obtained from alder buckthorn for the manufacture of explosives.

Ergot, of which large quantities are consumed by the British drug manufacturing industry, is supplied mainly by Portugal and Spain. It could be produced in Great Britain, the most favourable places for this purpose being in the west of England and in Wales. Already plans have been laid for experiments, and research workers are devoting attention to the selection of the species and strain of the fungus. It is satisfactory to know that the danger of a serious infection of cereals other than rye is slight. The aim is to select strains of high alkaloidal content, and it may be observed that much of the information concerning the alkaloidal content dates back to the time before the discovery of the alkaloid ergometrine. Chemical methods of analysis for differentiating water-soluble alkaloid (ergometrine group) from water-insoluble alkaloid (ergotoxine group) have been devised, and it seems desirable that cultivation experiments should be controlled on this basis. Incidentally, publications from the Pharmacopœia laboratory have indicated the possibility that the official standards of the British Pharmacopœia will be eventually on this basis.

Dill, which was formerly supplied largely from Germany, can be grown as a cover crop with caraway, the dill being harvested in the first year and the caraway in the second; similarly, coriander, which is already cultivated in England, may be used as a cover crop for caraway. With regard to gentian, which in normal times was imported from Italy, Spain and France, there are definite grounds for stating that it could be grown in Great Britain, but several years are needed to develop the large roots which are preferred in the London drug market. Lobelia, the present source of supply of which is the United States, can be grown on moderate to light soils in the southern half of England.

Coming now to the list of some forty vegetable drugs and essential oil-yielding plants which the Memorandum recommends for cultivation in some parts of the British Empire overseas, it is satisfactory to know that the following are already in production in India : nux vomica, podophyllum resin, rhubarb, belladonna, digitalis, henbane, jalap, lobelia, opium, squill, senna, santonin, karaya gum, and the following oils : arachis, eucalyptus, hydnocarpus and castor. The cultivation in India of psyllium and agar could also be developed, and there seems but little reason to doubt that some of the soils and climates of India are suitable for the cultivation of some of the other substances in the list set out by the Medical Research Council.

Australia, too, and New Zealand are countries which can supply some of Britain's needs for drugs. Such substances as digitalis, ephedra, ergot, liquorice, peppermint and pyrethrum, should repay investigation by cultivation in suitable places in Australia. The leaves of a tree indigenous to Australia contain hyoscyamine and hyoscine, and should prove a valuable source of these alkaloids. New Zealand is already a potential source of digitalis ; it is produced there in commercial quantities. The species of fungus which grows on Festuca orgot in New Zealand is esteemed as a source of ergotamine. Many other drugs in the list could be grown economically in that Dominion. Canada has not been a fruitful source of vegetable materia medica, but there is little doubt that some of the drugs which are supplied by the United States could be cultivated successfully in Canada. Another British country which has given good promise as a source of vegetab e drugs is Kenya, and it is understood that official encouragement will continue to begiven to experimentalstations in this colony. 